\title{
Enhanced Ethylene Selectivity Toward Hydrodechlorination of 1,2- Dichloroethane over Ag-Pd Bimetallic Catalysts
}

\author{
Jingya Sun ${ }^{1}$, Yuxiang Han ${ }^{1}$, Haiqin Wan ${ }^{1}$, Shourong Zheng ${ }^{1}$, Lin Dong ${ }^{2}$ \\ ${ }^{1}$ State Key Laboratory of Pollution Control and Resource Reuse, Jiangsu Key Laboratory of Vehicle Emissions Control \\ School of the Environment, Nanjing University \\ 163\# Xianlin Road, Nanjing, China \\ sunsun1118@126.com; hanyx2005@163.com; wanhq@nju.edu.cn; srzheng@nju.edu.cn \\ ${ }^{2}$ Jiangsu Key Laboratory of Vehicle Emissions Control, School of Chemistry and Chemical Engineering, Nanjing \\ University \\ donglin@nju.edu.cn
}

\section{Extended Abstract}

Recently, catalytic hydrodechlorination (HDC) of chlorinated volatile organic compounds (CVOCs) receives increasing attention because it is an environmentally friendly technique to convert CVOCs air pollutants into useful chemicals, olefins [1]. Then, improving the olefins selectivity of the catalysts for HDC of CVOCs has attracted considerable attention. We have studied the Pd-Ag bimetallic catalysts toward HDC of 1,2-dichloroethane to ethylene reaction.

We used surface reduction method to prepare $\mathrm{Pd}-\mathrm{Ag} / \mathrm{Al}_{2} \mathrm{O}_{3}$ catalyst, and evaluated their catalytic property toward HDC of 1,2-dichloroethane. As a result, Ag was deposited on the surface of Pd particles. With the increase of Ag content on the Pd surface led to the decrease of the amount of surface exposed $\mathrm{Pd}$ atoms. Thus, the $\mathrm{Pd}-\mathrm{Ag} / \mathrm{Al}_{2} \mathrm{O}_{3}$ catalyst showed a higher ethylene selectivity (95\%) than that prepared by conventional impregnated method (60\%), shown in figure 1 [2].
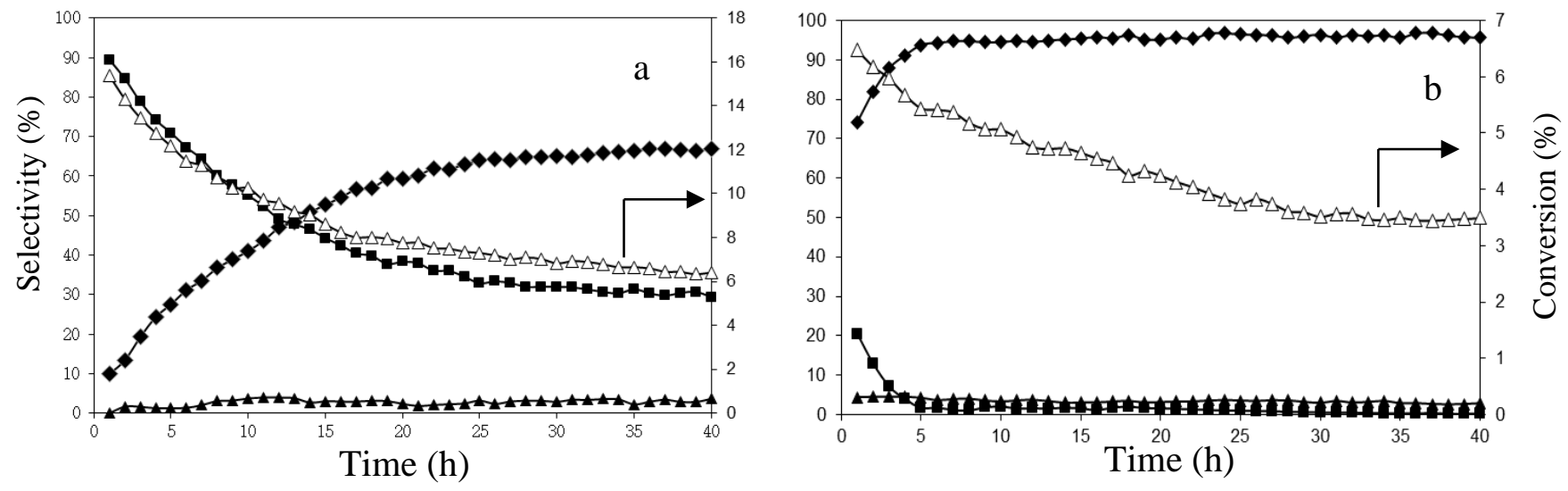

Fig. 1: The HDC of 1,2-dichloroethane over (a) im- $\mathrm{Pd}(0.97)-\mathrm{Ag}(0.97) / \mathrm{Al}_{2} \mathrm{O}_{3}$ and (b) $\operatorname{sr}-\mathrm{Pd}(0.94)-\mathrm{Ag}(0.96) / \mathrm{Al}{ }_{2} \mathrm{O}_{3}$ as a function of time on stream. $(\bullet)$ Ethylene; $(\boldsymbol{\bullet})$ Ethane; $(\boldsymbol{\Delta})$ Chloroethylene; $(\bullet)$ Chloroethane; and $(\Delta)$ Conversion.

Though the selectivity of ethylene was improved over the $\mathrm{Pd}-\mathrm{Ag} / \mathrm{Al}_{2} \mathrm{O}_{3}$ prepared by surface reduction method, most of the $\mathrm{Pd}$ was not utilized. To overcome this disadvantage, we used co-impregnated method to prepare $\mathrm{Pd}-\mathrm{Ag} / \mathrm{ZrO} \mathrm{C}_{2}$ catalyst with ultra low Pd loading. The results demonstrated that $\mathrm{Ag}(1.99)-\mathrm{Pd}(0.099) / \mathrm{ZrO}_{2}$ showed a higher ethylene selectivity because isolated Pd atom was majority species at this Pd loading [3].

To enhance the utilization of $\mathrm{Pd}$, very recently, we have prepared a series of $\mathrm{Pd}-\mathrm{Ag} / \mathrm{Al}_{2} \mathrm{O}_{3}$ catalysts with galvanic replacement method. This method is a thermodynamic spontaneous redox process driven by the difference between the 
standard electrode potentials of two metals, and extra reducing agents was unnecessary. The results indicated that the state of Pd was isolated sites, dimmer sites or clusters. When the replacement amount of Pd was below $0.13 \mathrm{wt} . \%, \mathrm{Pd}$ existed as isolated sites on the Ag surface, which showed a high ethylene selectivity (95\%).

It can be found that Pd-Ag bimetallic catalyst showed a high ethylene selectivity toward HDC of 1,2-dichloroethane when Pd formed isolated atom, and the state of Pd could be adjusted by the catalyst preparation method.

\section{Acknowledgments}

The financial supports from the National Key Research and Development Program of China (2016YFC0204301) and the Natural Science Foundation of Jiangsu Province (BK20151381) are gratefully acknowledeged.

\section{References}

[1] M. Bonarowska, Z. Kaszkur, D. Lomot, M. Rawski, Z. karpinski, "Effect of gold on catalytic behavior of palladium catalysts in hydrodechlorination of tetrachloromethane," J. Appl. Catal. B: Environ. vol. 162, pp. 45-56, 2015.

[2] Y. X. Han, G. F. Gu, J. Y. Sun, W. J. Wang, H. Q. Wan, Z. Y. Xu, S. R. Zheng, "Selective hydrodechlorination of 1,2-dichloroethane to ethylene overPd-Ag/Al2O3catalysts prepared by surface reduction," J. Appl. Surf. Sci. vol. 355, pp. 183-190, 2015.

[3] Y. X. Han, J. Y. Sun, H. Y. Fu, X. L. Qu, H. Q. Wan, Z. Y. Xu, S. R. Zheng, "Highly selective hydrodechlorination of 1,2-dichloroethane toethylene over Ag-Pd/ZrO2catalysts with trace Pd," J. Appl. Catal. A: Gen. vol. 519, pp. 1-6, 2016. 